\title{
ADVANCED OPTIMIZATION MODEL OF RESOURCE ALLOCATION IN THE B2C SUPPLY CHAIN
}

\author{
Firdaous Zair* - Naoufal Sefiani -Mohamed Fourka
}

Department of Mechanical Engineering, Faculty of Sciences and Technics, University of Abdelmalek Essaadi, Tangier, Morocco

\begin{tabular}{l}
\hline ARTICLE INFO \\
\hline Article history: \\
Received: 23.07 .2016$. \\
Received in revised form: 12.06 .2017$. \\
Accepted: 18.06 .2017$. \\
\hline Keywords: \\
E-commerce \\
B2C \\
Resource allocation model \\
Collaboration \\
Supply chain \\
\hline
\end{tabular}

DOI: https://doi.org/10.30765/er.38.3.10

\section{Introduction}

The development of online market and e-tailing has gained acceptance at a rapid pace, given its inherent advantages over traditional purchase process also due to in part to the busy mode of living. As predicted by Andrew J. Berger [1], E-commerce has fundamentally altered people's lifestyle and their

\begin{abstract}
:
Resource allocation plays a critical role in the strategic, tactical, and operational planning of the supply chain. The study focuses on aspects of resource allocation in the case of pure players, manufacturers, and Clicks \& Mortars that have launched online sales. These e-retailers offer a wide selection of customized services and so need an efficient management on every level and process.

The goal of the research was to explore a concrete approach to improve customer satisfaction, reduce costs and risks and to maintain the benefits of $e$ retailers and of its collaborators.

Our contribution is a decision support system and a tool to improve operational resources allocation in B2C supply chains. Hence, we started by modeling operations and the different scenarios. Then we introduced an optimization model founded on the analysis of resource allocation in $B 2 C$ supply chains and applicable on any $B 2 C e$ retailer. It helps in choosing the most optimal resources for each order. The model is based on a multi-objective optimization approach that takes into consideration the collaboration of resources throughout the supply chain operations process including dynamic costs and collaborator capabilities as well as associated risks and the quality of delivered services.
\end{abstract}

consumption behavior. Likewise, the structure of the supply chain has also evolved, and several new functions have taken form such as the e-procurement, e-ordering, and e-sourcing. New actors/participants have found their place in this new and evolving Supply Chain structure. The flexibility of ecommerce allows for a variety of intermediation aspects such as B2B and B2C marketplaces.

\footnotetext{
* Corresponding author. Tel.: 00212. 652.014.020;

E-mail address: zr.firdaous@gmail.com
} 
Additionally, it also allows for disintermediation from manufacturers like the direct-to-consumer looking to reach the final consumer directly or conversely i.e. direct to producer nascent from the client. With such disintermediation e-retailers are looking to remove intermediaries who take large commissions. An example is Amazon in the books retail sector as it seeks to eliminate the traditional publishing houses, setting up offers to authors to publish books easily and inexpensively.

The way of management of the supply chain has also changed $[2,3]$. The performance and sustainability of e-retailing depends on its capacity to adopt simple, flexible, inexpensive, and ecological supply chain processes. In order to maintain a competitive edge and provide a differentiated offering, E-retailers must ensure that they provide service diversity and quality [4 - 6] and they develop the level of trust of their customers [7]. In ordero maintain the margins and to be a long-term player, they must strengthen every link of their supply chains network [8] and manage well partner relationships and conflicts. So, an efficient supply chain network implies optimal allocation and integration of resources [9], such as banks and cash flow / payment companies, suppliers, manufacturers and third party logistic companies (3PL). Selection of the appropriate collaborators provides the necessary customized services [10] with less onerous delivery process and leads to higher customer satisfaction.

Several recent studies have addressed different aspects of B2C supply chain problems [11 - 21]. However, very little research has attempted to address the optimization of the of e-commerce resource allocation [10, 20 - 23].

This paper does take into consideration prior research and offers for the first time in the literature a general model for resource allocation at the operational level, this model is applicable on any B2C e-retailer, it considers all possible strategies of collaboration, customization, inventory ownership, management and preparation of orders, delivery and of returns. Technically, contrary to the Yao \& Gu (2015) model [20] that imposes the realization of each activity in the order management cycle using only one collaborator, the study proposes instead that the activities (steps) can be decomposed into several operations. In our proposed model, multiple resources (internal or external) can cooperate in the execution of one step if it enables more efficient results which can be found by applying the model on one of the new optimization approaches like ASAPSPSA method [24].
Our model incorporates the specificities and characteristics of both the online shopping and the online seller. The online seller is assumed to be a manufacturer, a click and mortar or a pure player (Figure 1). We also consider the option to have orders that are urgent and have pre-determined fixed deadlines. We provide customization options of the provided products and services. We incorporate dynamic costs of activities that depend on the season of its elaboration and on both the value and frequency of all activities allocated to the executer and to its partners.

\section{Patterns and trends}

To achieve a general model of B2C supply chain resource allocation, it was necessary to bundle all scenarios and logistics practices of electronic traders, hence the interest of this part.

The structure of the global supply chain has evolved with on-going developments in e-commerce (Figure 1), to take many forms and the customer now has options to purchase from multiple available channels. Several scenarios are therefore possible for collaboration to conduct commerce to process and service between the e-retailer and the customers.

The actual products can be warehoused by the eretailer or its supplier or both. In the first case, products can be:

- warehoused in the e-retailer warehouses alongside traditional sales or dedicated to online shopping only. This model would lead to a higher performance, but it requires a larger investment.

-or stored in the e-retailer stores in the case of a click and mortar retailer. This model shortens the processing cycle time but generates inventory holding costs. The outstanding question is how critical is the delivery time.

The order pickup can be performed by the e-retailer or by the suppliers. Obviously, decisions regarding the inventory ownership affect the order of preparation because it should be executed where the stocks are located.

Later, the allocation of assembling executer is also strongly impacted by previous decisions. The order can be assembled in the supplier or retailer or thirdparty platforms. In fact, if the pickup takes place at the retailer warehouses or stores, assembly of the order will be held in its platforms. However, if the pickup is in the supplier's, orders can be assembled either by the supplier or in the warehouse of the retailer or of the third party. 


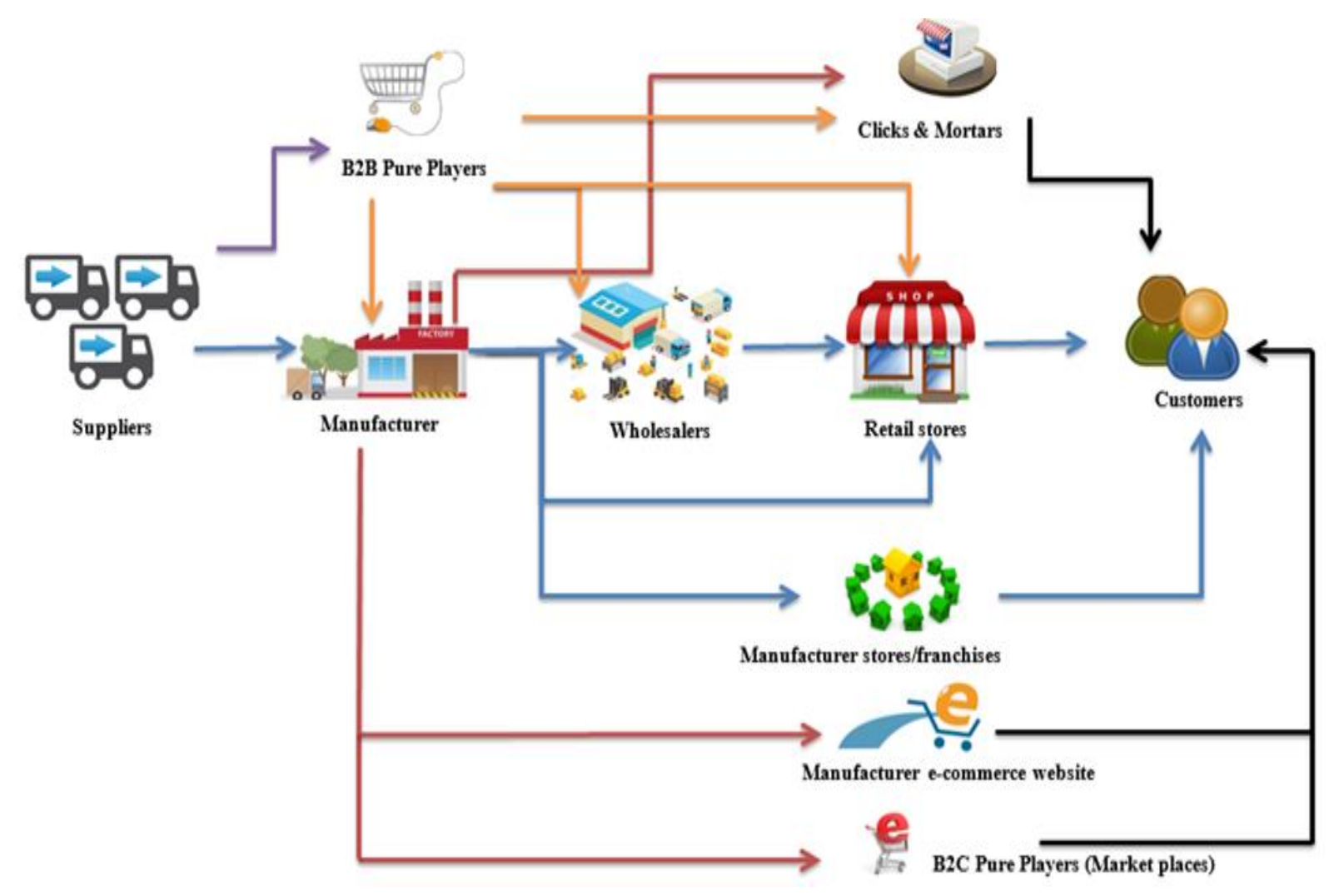

Figure 1. The global supply chain integrating e-commerce players.

Finally, the delivery can be accomplished by the retailer, the third party or the supplier. The last case is known by 'the drop shipping' where the supplier is responsible for all the order processing.

The delivery process is a vital element in $\mathrm{B} 2 \mathrm{C}$ supply chains $[4,18,25]$ that had considerably evolved. Now we talk about:

-Pick up in-store: the clicks and Mortars choose to take advantage of the densities of their stores' network. Then they offer home delivery as they suggest the pick-up in-stores or the drive-through.

-Warehouse preparation and home delivery.

-Depot-pickup: Preparation in depots and pick-up: customers pick up their orders from depots.

-Delivery to relay points: customers pick up their order from a local store: grocery store, gas station, dry cleaners ... Those points usually offer wide ranges of opening hours and the customer is notified of arrival of the order by SMS, a call, email or even by voice message.

-The lockers: automatic system that allows the customer to pick up his purchases twenty-four seven.

-City logistics and urban distribution centers.
From all these trends and practices B2C supply chain structures can be summarized in two basic models, where Model 1 is the order pickup in warehouses (Figure 2), and Model 2 is for order pickup in stores which is adopted by clicks and mortars (Figure 3).

\subsection{Discussion}

It's realized that in all these scenarios, operations are the same and business processes do not change. Sourcing, order preparation, assembly, packaging, delivery, return, payment are the main activities in the B2C order management cycle. Except that according to the nature of sellers, orders, and the products offered, it is possible that some transactions do not exist or that others may be added. For example, a manufacturer could allow a consumer to customize its product, as a florist allows a customer to virtually create a bouquet. Product customization process will be added which may not exist in other B2C supply chains. 


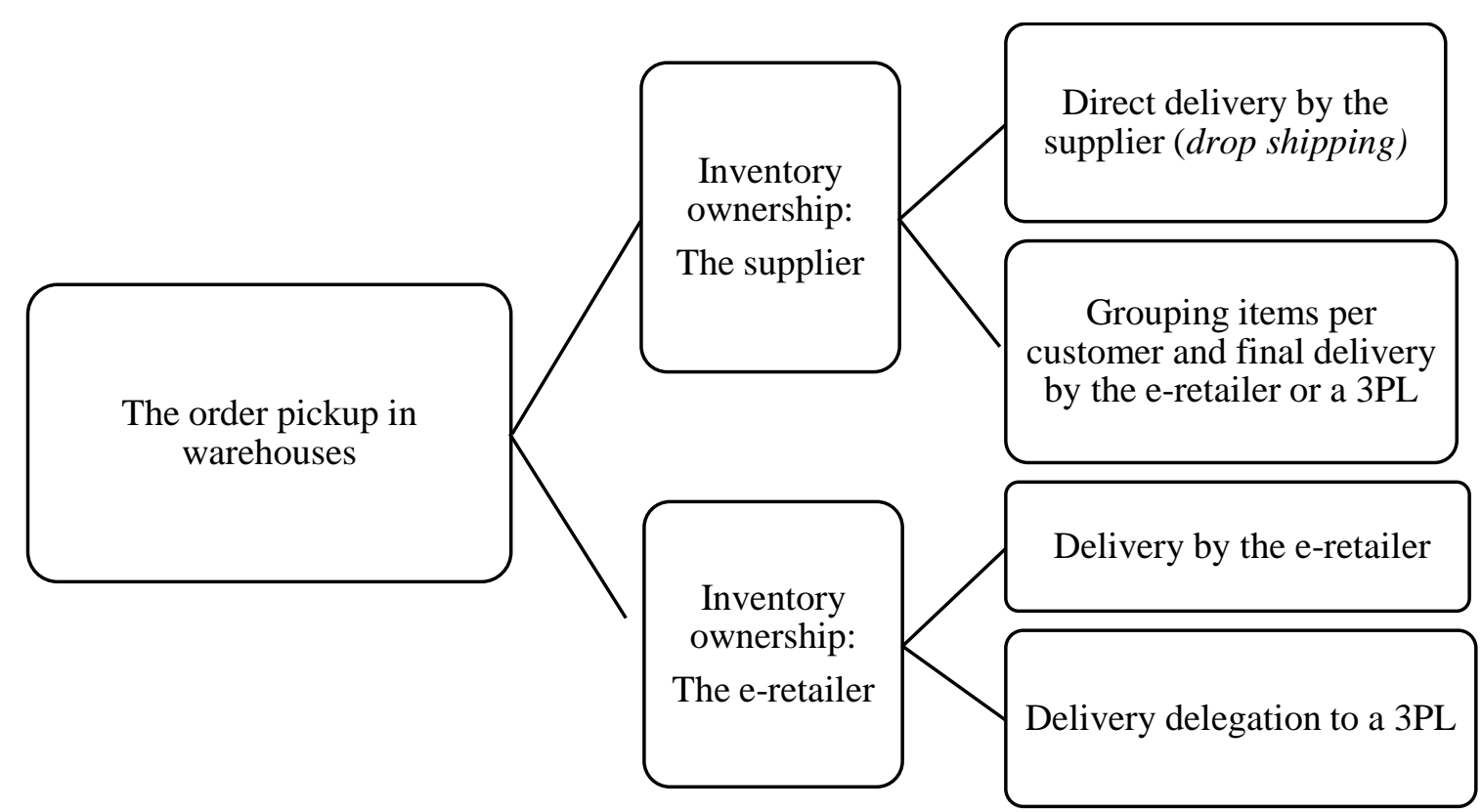

Figure 2. Order pickup in warehouses.

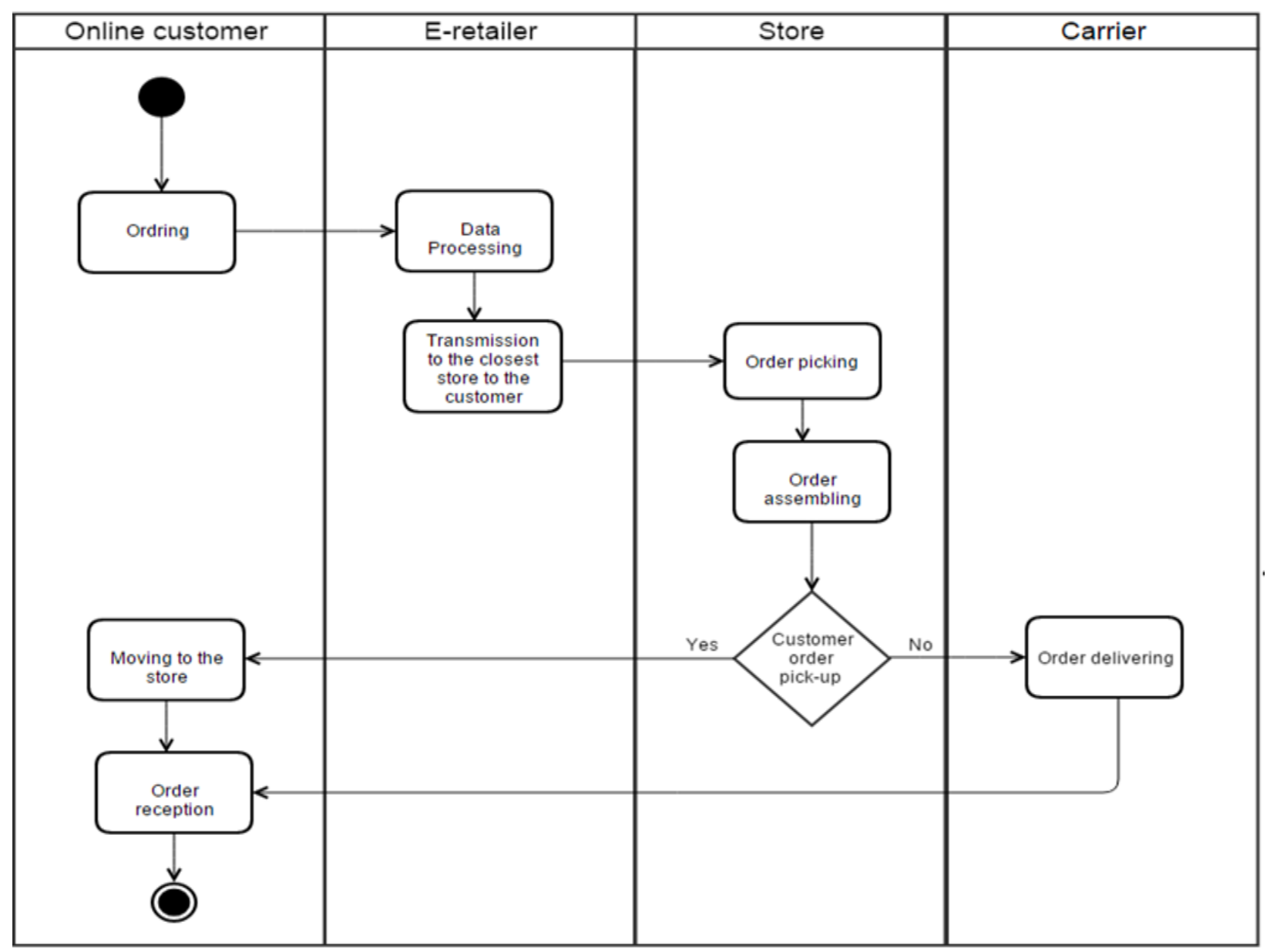

Figure 3. Modeling of the order store picking. 
So, a conceptual model for the global B2C supply chain including all the cases can be created. However, what is multiplying structures is the variation of the places where these activities are developed and the diversity of possible resources and executors witch all are strategically chosen. The big concern is to have powerful and properly optimized supply chain structures which requires assignment of tasks and processes to the most appropriate executors. The selection of those collaborators does not end at the strategic level but must be extended to the operational one which becomes a very critical level of decision. Because of the B2C retailing constraints, the customer requests incertitude, the multiple delivery destinations, the necessity of the multiplication of customized services, the customer requirements, the conditions of each collaborators, the variation in costs of operations for order processing and the products diversity...

\section{Optimization method}

\subsection{Assumptions}

An order contains information about ordered products: References, quantities, packaging, payment, shipping address: home, relay point, drivethrough, etc. and type of delivery: urgent, in time slots, fixed deadline or hybrid order deadlines (in the same order, products can have different types of deliveries) (Figure 4).

Usually on online purchase, the customer hopes to have the order in the time that suits him and in the desired place. Some orders might be urgent, the customer can even pay more, and his only concern is to be delivered as soon as possible. In some cases, the customer is seeking to get the order at a specific time, being delivered later or earlier will not be appreciated.

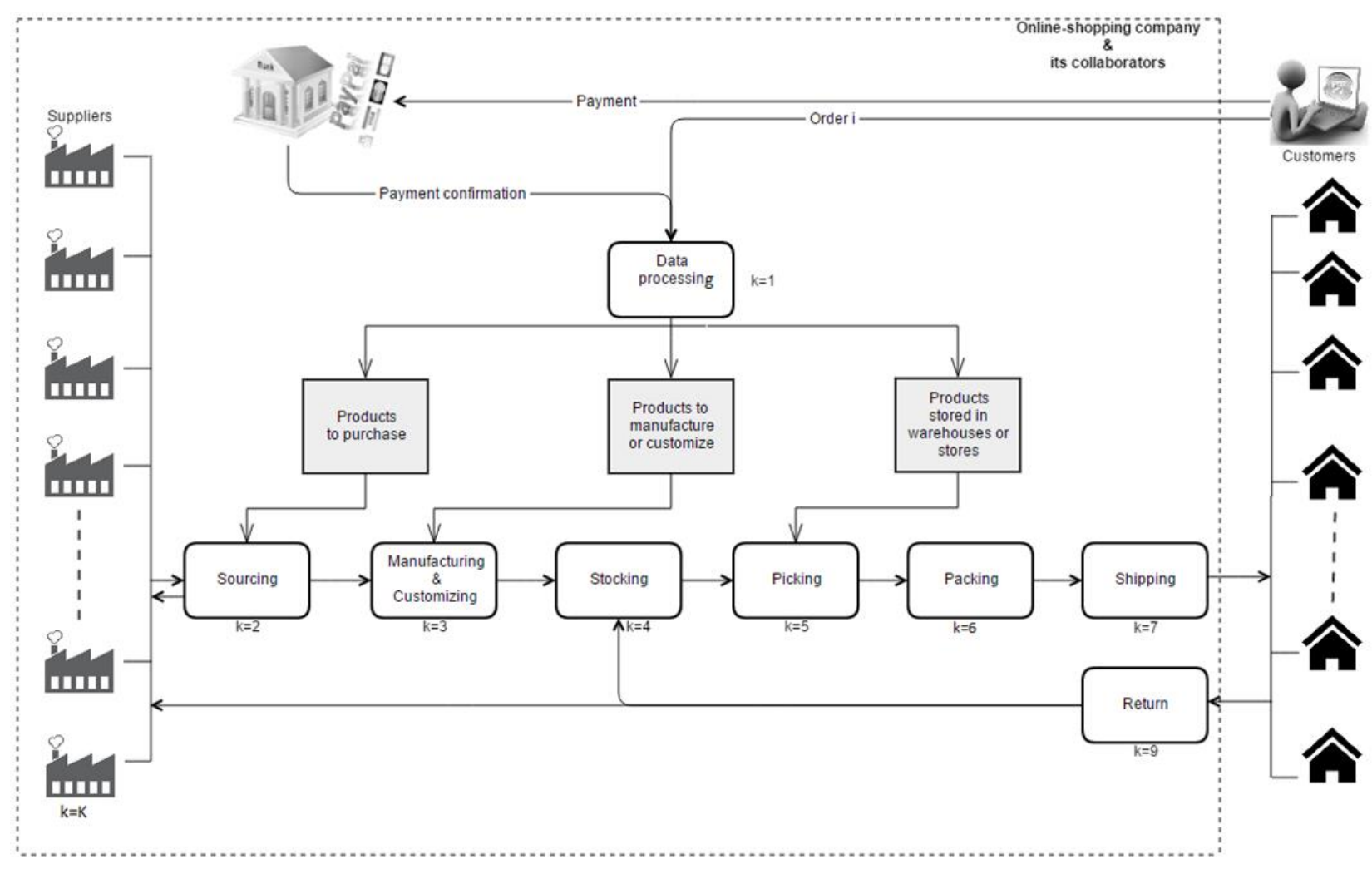

Figure 4. E-supply Chain diagram.

While in other cases, the customer requires time ranges for delivery. In this case, the deadline is not fixed but it's in a time window. For example, during home deliveries, the customer may not be available all day at home. If the time ranges are not respected, home delivery can fail, and the carrier must come back with the risk of failing again. We consider only urgent orders and those with specific deadlines in our model. 
To build the optimization model for allocating resources in a B2C e-commerce context of personalized services, we made the following assumptions:

$\mathrm{I}$ is the number of the unprocessed orders of B2C eretailer in the period $\mathrm{T}$ and $\mathrm{i}$ is the index of each order; $\mathrm{i}=(1,2 \ldots \mathrm{I})$.

$t_{s}$ is the time of start of operations to meet these orders.

$\mathrm{K}$ is the number of steps to fulfill an order and $\mathrm{k}$ is the index of each step.

$N_{k}$ is the number of cooperators who can participate to accomplish the step $\mathrm{k}$ and $\mathrm{r}$ is the index of each cooperator.

$\mathrm{N}$ is the number of the e-retailer's cooperators, $\mathrm{r}=(1$, $2 \ldots \mathrm{N}) . R_{k}(r)$ is a function such as $R_{k}(r)=1$ if one of $r$ activities matches with operations in the step k, otherwise $R_{k}(r)=0$. Thereby, $\sum_{r=1}^{r=N} R_{k}(r)=N_{k}$

A step can be accomplished by one or many collaborators. In order to not repeat the same operations of the step $\mathrm{k}$ of the order $\mathrm{i}$, we will call sub-steps according to the specifications and needs of the order $i$ and the overall conditions. So, every step $\mathrm{k}$ of the order i is composed of $J_{k i}$ operations.

$j_{k i}$ is the index of each operation in the step $\mathrm{k}$ of the order i: $j_{k i}=\left(1,2, \ldots, J_{k i}\right)$

The operation $j_{k i}$ can be executed by only one cooperator.

A cooperator can make several operations in several stages. The operations in the step $\mathrm{k}$ of the order $\mathrm{i}$ can be:

- Serial operation if every $\left(j_{k i}+1\right)$ can only start when the $j_{k i}$ operation is completed.

- Parallel if the operations are independent (Figure 5).

If there is hybrid in one step, there are sSerial and parallel operations. (Figure 6)

$C_{j_{k i} r}$ is $j_{k i}$ processing cost of the collaborator r. It's a function which depends on the period where $j_{k i}$ is processed, the other operations that $r$ will be responsible for in a given period and the selection of other collaborators with whom it is going to participate in the order processing.
It is supposed that the maximum processing cost expected by the e-retailer for k of step i is $C_{e k i}$.

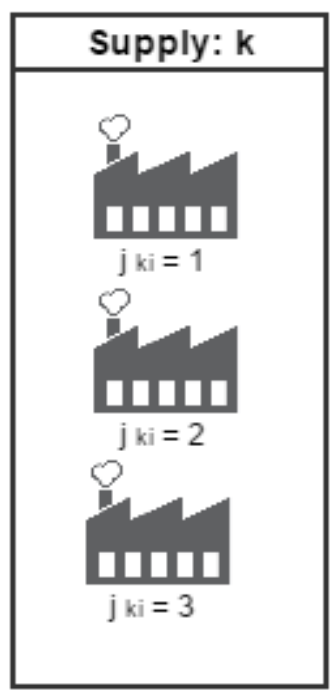

Figure 5. Example of parallel operations.

$T_{D i}$ is the maximum time specified by the e-retailer for processing the order $\mathrm{i}$.

$T_{j_{k i} r}$ is the time that the collaborator $\mathrm{r}$ needs for processing the operation $j_{k i}$.

$T_{e_{j_{k} r} r}$ is the collaborator expected time for the processing of the operation $j_{k i}$.

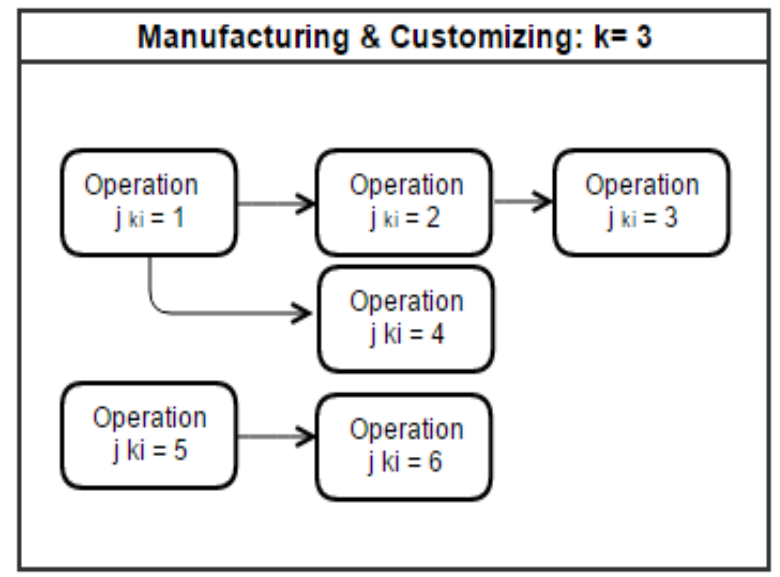

Figure 6. Example of hybrid operations.

$T_{k i}$ is the step $\mathrm{k}$ processing time by the selected collaborators. 
$T_{e k i}$ is the expected time for step $\mathrm{k}$ processing by selected collaborators. We suppose that it is equal to zero when the order is urgent.

$\varepsilon$ is a coefficient of tolerance related to time, in case of an unexpected event during orders processing.

$\alpha_{j j_{k i}}$ is a variable such as $j=\left(1,2 \ldots, J_{k i}\right)$, $\alpha_{j j_{k i}}=1$ if $j=j_{k i}$ or $j$ is serial with $j_{k i}$, else $\alpha_{j j_{k i}}=0$.

The minimum required quality for the operation $j_{k i}$ is $Q_{m_{i n} j_{k i}}$ and the quality that can provide $\mathrm{r}$ for $j_{k i}$ is $Q_{j_{k i} r}$.

$B_{j_{k i} r}$ is the collaborative expected benefit of the eretailer if he chose the collaborator $r$ for the processing of $j_{k i}$, this function also depends on the period where $j_{k i}$ is processed, the other operations that $r$ will be responsible for in a given period and the selection of other collaborators with whom it is going to participate in the order processing.

$B_{c j_{k i} r}$ is $\mathrm{r}$ collaboration benefit for processing the operation $j_{k i}$ and $B_{c_{\text {min }} j_{k i} r}$ is the minimal acceptable benefit by $\mathrm{r}$ to do the operation $j_{k i}$.

$A_{k r}$ is $\mathrm{r}$ collaboration capacity for the step $\mathrm{k}$ in the period of processing of the I orders and $A_{j_{k i} r}$ is the needed capacity to process $j_{k i}$ by the collaborator $\mathrm{r}$. $R_{j_{k i} r}$ is the e-retailer collaboration risk to choose the collaborator $\mathrm{r}$ to do the operation $j_{k i}$ and $R_{c j_{k i} r}$ is $\mathrm{r}$ collaboration risk to execute the operation $j_{k i}$ and $R_{c_{\text {max }} j_{k i} r}$ is the r maximal acceptable collaboration risk for $j_{k i}$ processing.

$g_{j_{k i} r}$ is a variable such as $g_{j_{k i} r}=1$ if the e-retailer choose $\mathrm{r}$ for the processing of $j_{k i}$ and $R_{k}(r)=1$ otherwise $g_{j_{k i} r}=0$.

\subsection{Optimization model}

The optimization model is using the following objective functions:

$$
\operatorname{Min} F_{1}=\sum_{j_{k i}=1}^{J_{k i}} \sum_{k=1}^{K} \sum_{i=1}^{I} \sum_{r=1}^{N} C_{j_{k i} r} g_{j_{k i} r}
$$

$$
\operatorname{Max} F_{2}=\sum_{j_{k i}=1}^{J_{k i}} \sum_{k=1}^{K} \sum_{i=1}^{I} \sum_{r=1}^{N} B_{j_{k i} r} g_{j_{k i} r}
$$

$$
\operatorname{Min} F_{3}=
$$

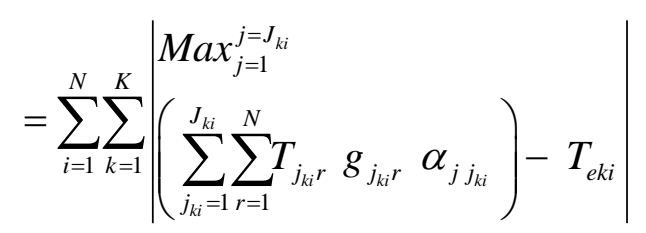

$$
\operatorname{Min} F_{4}=\sum_{j_{k i}=1}^{J_{k i}} \sum_{k=1}^{K} \sum_{i=1}^{I} \sum_{r=1}^{N} R_{j_{k i} r} g_{j_{k i} r}
$$

Subject to:

$$
\begin{aligned}
& B_{c_{\text {min }} j_{k i} r} \leq B_{c_{j_{k i} r}} \\
& R_{c_{k_{k i} r} r} \leq R_{c_{\max } j_{j i} r} \\
& Q_{\min _{k i}} \leq Q_{j_{k i} r}
\end{aligned}
$$

$$
\sum_{j_{k i}=1}^{J_{k i}} \sum_{i=1}^{I} \sum_{r=1}^{N} A_{j_{k i} r} g_{j_{k i} r} \leq A_{k r}
$$

$$
\sum_{r=1}^{N} \sum_{j_{k i}=1}^{J_{k i}} g_{j_{k i} r}=J_{k i}
$$

$$
\sum_{r=1}^{N} g_{j_{k i} r}=1
$$

$$
T_{k i}=\operatorname{Max}_{j=1}^{j=J_{k i}}\left(\sum_{j_{k i}=1}^{J_{k i}} \sum_{r=1}^{N} T_{j_{k i} r} g_{j_{k i} r} \alpha_{j j_{k i}}\right)
$$

If the order $i$ is urgent:

$$
\sum_{k=1}^{K} T_{k i} \leq(1+\varepsilon) T_{D i}
$$

If the order i has a fixed deadline:

$$
T_{D i}(1-\varepsilon) \leq \sum_{k=1}^{K} T_{k i} \leq T_{D i}(1+\varepsilon)
$$




$$
\sum_{j_{k i}=1}^{J_{k i}} \sum_{k=1}^{K} \sum_{r=1}^{N} C_{j_{k i} r} g_{j_{k i} r} \leq \sum_{k=1}^{K} C_{e k i}
$$

Such as:

$$
\begin{aligned}
& g_{j_{k i} r}=1 \operatorname{or} 0 ; R_{k}(r)=1 \operatorname{or} 0 ; \alpha_{j j_{k i}}=1 \operatorname{or} 0 ; \\
& \mathrm{i}=1,2, \ldots, \mathrm{I} ; \mathrm{r}=1,2, \ldots, \mathrm{N} ; j_{k i}=\left(1,2, \ldots, J_{k i}\right) ; \\
& k=(1,2, \ldots, K) .
\end{aligned}
$$

\subsection{Model interpretation and analysis}

We consider that the cost of each step is dynamic because the cost of an operation depends on the time and the season of its elaboration. For example, night work and holidays costs are necessarily higher and costs in the highest retail sale days, like Black Fridays and Cyber Mondays, must be different from the costs of low seasons. The objective function (1) is for the minimization of total cost order operations processing in a period $\mathrm{T}$. The cost of an operation depends also on the value and quantity of all operations that the e-retailer allocates to its collaborator and its partners around a period determined by both. This cost can be influenced by the other resource allocation decisions; for collaborators, contributing in the treatment of a process with a competitor partner is preferable and could be cheaper. For example, physical transactions and information sharing between the concurrent carriers, which share resources such as trucks, warehouses, and cross docking distribution systems are easier, more fluid and can be less expensive than when they are treating a process with a non-partner concurrent.

The benefit is the margin between the cost and the price, so it is also a dynamic function that depends on the time operations processing and processes that collaborators and their partners will be instructed to do together in a given period. The objective function (2) maximizes the benefits of the e-retailer.

For urgent orders, it is needed to minimize all steps of processing time, but if they have a specific deadline, it's needed to minimize the difference between the expected time and the actual time. The orders' processing time optimization function (function (3)), considers the two cases.

The objective function (4) seeks to reduce the eretailer collaborative risks and the formula (5) is the collaborator benefit constraints to ensure its satisfaction and the formula (6) as the risk constraint collaborator.

The quality provided by the selected collaborator must be higher or equal to the minimum quality required by the e-retailer, so we added the formula (7) for the quality constraint.

When choosing collaborators for an operation, it is needed to check the capacity dimension and consider the other operations affected to him for the period of this operation processing. The formula (8) is the capacity constraint; a collaborator chosen to handle similar or different operations of one or several orders that must have the ability to execute all these operations.

The constraints (9) (10) ensure that each step will be executed and each operation will be done by only one employee, thereby guaranteeing that the same operation and processes will not be repeated.

For urgent orders, the duration of the order processing should not exceed the deadline set by the e-retailer with a tolerance time, the formula (11) is its deadline constraint.

The formula (12) is the deadline constraint for fixed shipping deadline orders. The duration of the order processing should not come out of an interval set by the e-retailer to deliver in the expected time by the customer. Delivering the order too earlier or too late can be a non-quality indicator. Finally, the formula (13) ensures that the order cost will not exceed the cost expected by the e-retailer.

By considering all those constraints the proposed operational model can be applied to any B2C supply chain regardless the nature of the seller, the marketed products, the services offered, and all possible patterns and strategies.

\section{Conclusion}

Today's B2C companies offer customized services according to customer's needs to find their viability in markets dominated by oversupply, hyper competition, and uncertain volatile demand. They are under the obligation to integrate the consumer within the design of products, to deliver him wherever and whenever he wants to for the lower cost and to provide customer support. In this paper, we propose an optimization model for allocating resources, regardless of the seller's nature, the retailed products, and the services offered. We consider various aspects and characteristics of the B2C supply chain. We also include orders with urgent and specific deadline., The case of delivery time slots deadlines will be held in our upcoming researches. Furthermore, we take into 
account that each order processing step can be executed by one or many resources (internal or external collaborators) and, depending on many factors, it can be decomposed into many parallel, serial or hybrid activities. Finally, our optimization model is also based on dynamic costs, service quality, and collaborator capacities and risks.

\section{Future works and research direction}

For future work, we intend to apply this model to pure player, manufacturer, and Clicks \& Mortar e-retailers and analyze the specificities of each case of study. Then, by using these results and by combining Nash equilibrium and Blockchain technology, we intend to realize an improved strategic and operational efficient B2C resource allocation system.

Based on the new reviewed papers and on the new management trends and technologies, an important future research direction is proposed: Blockchain and smart contracts are applied on the B2C supply chains, since the experts of this technologies promise not only highly secure cash and information flows but also agile and low cost logistic processes.

\section{References}

[1] Berger, A. J.: E-commerce and supply chains breaking down the boundaries (2002).

[2] Boone, T., Ganeshan, R.,: The frontiers of eBusiness technology and supply chains. Journal of Operations Management 25 (2007), 11951198

[3] Vukovic, A., Ikonic, M. Dobovicek, S.: Reconfigurable manufacturing system and the need for new Taylorism. Engineering Review. 30, 2, (2010), 71-82

[4] Mu-Chen, C., Chia-Lin, H., Chih-Ming, H., Ying-Yi, L.: Ensuring the quality of e-shopping specialty foods through efficient logistics service, Trends in Food Science \& Technology 35 (2014), 69-82.

[5] Fassnacht, M., \& Koese, I.: Quality of electronic services: conceptualizing and testing a hierarchical model. Journal of Service Research, 9 (2006), 19-37.

[6] Lee, F. H., Wu, W. Y.: Moderating effects of technology acceptance perspectives on e-service quality formation evidence from airline websites in Taiwan. Expert Systems with Applications, 38 (2011), 7766-7773.
[7] Bartikowski, B., Singh, N., Doing E-Business in France: Drivers of Online Trust in Business-toConsumer Websites. Glob. Bus. Org. Exc., 33 (2014): 28-36. doi: 10.1002/joe.21551.

[8] Boyer, K. K., Hult, G. T.: Extending the Supply Chain: Integrating Operations and Marketing in the Online Grocery Industry. Journal of Operations Management 23 (6) (2005): 642-661.

[9] Frohlich, M., Westbrook, R.: Demand chain management in manufacturing and services: Web-based integration, drivers and performance. Journal of Operations Management 20 (2002), 729-745.

[10] Yao, J. M.: Supply chain resources integration optimization in B2C online shopping, International Journal of Production Research (2015).

[11] Meng, Y.: Supply Chain Management under ECommerce Environment, International Journal of Innovation. Management and Technology vol. 3, no. 3, (2012), pp. 210-212.

[12] Tsai, J. Y., Raghu, T. S., Shao, B. B. M.: Information systems and technology sourcing strategies of e-Retailers for value chain enablement. Journal of Operations Management (2013). http://dx.doi.org/10.1016/j.jom.2013.07.009

[13] Durand, B., Gonzalez-Feliu, J. , Henriot, F. : La logistique urbaine, facteur clé de développement $d u B$ to $C$. Logistique \& Management, 18 (2), (2010), pp.7-19.

[14] Rao, S., Griffis, S.E., Goldsby, T. J.: Failure to deliver? Linking online order fulfillment glitches with future purchase behavior. Journal of Operations Management 29 (2011), 692-703

[15] Dongmei, H.: The Logistic Strategy Based on Ecommerce. Management Science and Industrial Engineering (MSIE) (2011).

[16] Suchánek, P., Bucki, R.: Method of Supply Chain Optimization in E-commerce. Journal of Applied Economic Science, Vol. VI, Issue 3(17), Fall 2011: $257-263$.

[17] Wang, H.: Li, H.: Research on Models and Modernization of Logistic System in Ecommerce. International Conference on Management, Education and Social Science (2014).

[18] Weltevreden, J.W. J.: B2C e-commerce logistics: the rise of collection-and-delivery points in the Netherlands. International Journal of Retail \& Distribution Management, 36(8), (2008), 638660 . 
[19] Gevaers, R., Van de Voorde, E., Vanelslander, T.: Cost Modelling and Simulation of Last-mile Characteristics in an Innovative B2C Supply Chain Environment with Implications on Urban Areas and Cities. 8th International Conference on City Logistics, Procedia - Social and Behavioral Sciences 125 (2014), 398 - 411.

[20] Yao, J., Gu, M.: Optimization Analysis of Supply Chain Resource Allocation in Customized Online Shopping Service Mode. Mathematical Problems in Engineering (2015), Article ID 519125.

[21] Dogan, E., Payidar Akgungor, A., Arslan, T.: Estimation of delay and vehicle stops at signalized intersections using artificial neural network. Engineering Review 36(2) (2016), 157-165.

[22] Xue, X., Wang, Y., Shen, Q., Yu, X.: Coordination Mechanisms for Construction Supply Chain Management in the Internet Environment. International Journal of Project Management 25 (2) (2007): 150-157.
[23] Location Model with Online Demand Pooling in a Multi-Channel Supply Chain. European Journal of Operational Research 207 (1) (2010): 218-231.

[24] El Hami, A., Kadry, S.: Global optimization method for design problems. Engineering Review 36 (2) (2016), 149-155.

[25] Liao, S. H., Chen, Y. J., Lin, Y. T.: Mining customer knowledge to implement online shopping and home delivery for hypermarkets. Expert Systems with Applications, 38 (2011), 3982-3991. 